\title{
LIFE HISTORY TRAITS AND NATURAL SELECTION FOR SMALL BODY SIZE IN A POPULATION OF DARWIN'S FINCHES
}

\author{
Trevor D. Price and Peter R. Grant \\ Division of Biological Sciences, The University of Michigan, Ann Arbor, Michigan 48109
}

Received December 27, 1982. Revised August 16, 1983

Application of the theory and methods of quantitative genetics to life history studies has led to a focus on the measurement of phenotypic and genetic covariances between life history traits (Stearns, 1980, 1982a, 1982b; Dingle and Hegmann, 1982 p. 231-244; Etges, 1982; Giesel et al., 1982; Hegmann and Dingle, 1982; Lande, 1982; Rose, 1983). These covariances are the essential parameters in theoretical models describing the evolution of such traits. Estimation of genetic covariance is based on the resemblance between relatives. Genetic covariances have usually been estimated in the laboratory where the environment is controlled and the main cause of mortality is often senescence. Covariances are less easy to estimate in nature because environmental correlations are likely to fluctuate greatly in magnitude and sign with changing conditions (Lande, 1982) and because causes of mortality also vary. Thus direct estimates of genetic covariances between life history traits will vary (Giesel et al., 1982; Stearns, 1982a, 1982b).

In this paper we adopt an alternative, indirect, approach to estimating covariances between life history traits in natural populations. It depends on the measurement of selection on a morphological character at two life history stages, and the assumption that much of the variance in fitness at each stage is due to variance in the character or characters upon which selection acts. Two life history traits, such as probability of survival over two given developmental stages, may be said to covary if they are each determined by the same morphological character or characters. The size and direction of the covariance can be qualitatively estimated from the magnitude and directions of selection. Further, if the morphological character is found to be highly heritable it can be inferred that the two life history traits covary genetically.

Boag and Grant (1981) observed intense natural selection favoring large beak and body size in a population of Darwin's Medium Ground finches, Geospiza for$t i s$, associated with adult mortality during a drought. The main cause of mortality was starvation, and differential survival with respect to morphology was at least partly a reflection of differential handling ability of the foods remaining in the environment (Boag and Grant, 1981). Since size measures are highly heritable, with some highly repeatable measures such as beak depth having heritabilities of over .8 (Boag and Grant, 1978; Boag, 1983), the probability of adult survival with respect to size characters is also expected to be a highly heritable character, provided that adult mortality based on size results from the same general causes in different generations.

In this paper we consider the possibility of selection on body size at other stages of the life cycle. Specifically we ask, was the directional selection an isolated event with long term evolutionary consequences, or is it balanced by selection favoring small body size at other stages of the life cycle? To answer this question we examine the possibility of selection on body size associated with juvenile mortality. If selection at this life history stage is found we can follow the reasoning developed above. In particular we can argue that probability of juvenile survival is heritable, and genetically negatively covaries with probability of adult survival. In doing so, we assume juvenile 
and adult body size are highly correlated, and are in essence a single trait, so that large juveniles produce large adults and small juveniles produce small adults. Juvenile and adult body size are known to be highly genetically correlated in this species (Boag, 1983; Price, unpubl.) and in another Darwin's finch species, Geospiza conirostris (Grant, 1981a).

\section{Methods}

The 40 hectare island of Daphne Major, Galápagos, and its finches are described in Grant et al. (1975) and Boag (1981). An intensive breeding study of the $G$. fortis population on the island was started in June 1975 by P. R. Grant and P. T. Boag. Between 1976 and 1981 finches were studied for a large proportion of the first 6 months of each year by P. T. Boag (1976-1978) and T. D. Price (1979-1981).

Seed Abundance.-In December or January and May or June of each year, seeds on plants and in the soil were counted in 50 randomly chosen $1 \mathrm{~m}^{2}$ square quadrats (Boag, 1981). Boag (1981) gives dry weights, seed depths (in $\mathrm{mm}$ ) and hardness (in Kgf) for all Daphne seeds. Seed depth $(D)$ and hardness $(H)$ have been combined into a single index as their geometric mean $(\sqrt{D H}$, Abbott et al., 1977).

Finch Population Sizes and Assessments of Emigration.-Finches were trapped in mist nets, measured, given a numbered metal band and a unique combination of plastic color bands, and released unharmed. A list of all known color-banded birds alive on the island was compiled at the same times as seed abundance was measured. Population sizes were assessed in the years 1975-1978 from the ratio of banded to unbanded finches observed on a two-morning walk over the whole of the island (Boag and Grant, 1981). The proportion of colorbanded birds rose from $20 \%$ in 1975 , to $70 \%$ in 1978 , then to $90 \%$ in 1979 and up to $95 \%$ in 1981 . In the years $1979-$ 1981 the number of unbanded birds was
TABLE 1. Breeding and study periods 1975-1981. Periods of study are B-studied in the breeding season, $\mathrm{PB}-$ studied in the post breeding season when juveniles are 2-4 months old. All populations were also studied in the following January. NAnot applicable. * All juveniles died within one month of fledging in 1980 .

\begin{tabular}{lccl}
\hline Year & $\begin{array}{c}\text { Rainfall } \\
(\mathrm{mm})\end{array}$ & $\begin{array}{c}\text { Approximate } \\
\text { number of } \\
\text { broods per pair }\end{array}$ & $\begin{array}{c}\text { Periods of } \\
\text { study }\end{array}$ \\
\hline 1975 & $?$ & 2 & PB \\
1976 & 135 & 1 & B, PB \\
1977 & 24 & 0 & NA \\
1978 & 137 & 3 & B, PB \\
1979 & 69 & 1 & B \\
1980 & 53 & $1 *$ & NA \\
1981 & 73 & 1 & B, PB \\
\hline
\end{tabular}

accurately known and population sizes assessed by direct count.

We visited Isla Daphne Minor, $6 \mathrm{~km}$ from I. Daphne Major, in May 1979 (Grant et al., 1980) to assess the importance of migration between islands. A thorough search was made for finches that had been banded on I. Daphne Major; additionally, approximately half the finches present there were color-banded.

Finch Breeding. - Reproduction is determined by rainfall (Grant and Boag, 1980). Reproductive success and the periods of study are summarized in Table 1. Most nests were discovered while still under construction and marked with flagging tape. Nest contents were checked regularly to obtain information on laying date, clutch size and fledging success. All nestlings were weighed and banded with a single metal band at 8-10 days old, and since 1978 they have been uniquely color-banded at this time as well. The proportion of all active nests discovered was estimated, from the proportion of banded juveniles in post-breeding flocks, to have been $50 \%$ in $1976,85 \%$ in 1978 and over $95 \%$ between 1979 and 1981 .

Breeding and Feeding Behavior.-Between 1979 and 1981 data were collected on nest attendance, seed handling ability and feeding rates. Feeding observations were made on individually marked birds, timed with a stopwatch. 
TABLE 2. Repeatability measures for Geospiza fortis. The first three columns compare measures taken by P. T. Boag only (PTB), T. D. Price (TDP), and one measure by PTB and one by TDP (PTB-TDP). Sample sizes are the number of individuals for which paired measures are available, which varies slightly between characters. Mean differences are the average differences between measurements taken by TDP and PTB separately for (a) adults and (b) birds measured as juveniles by PTB in 1978, and subsequently as adults by TDP. Each number in parentheses is the difference expressed as a percentage of the total size. Significance values are from paired $t$ tests. ${ }^{* *} P<.01$. Heritabilities are from Boag (1983).

\begin{tabular}{lccccccc}
\hline & \multicolumn{3}{c}{ Repeatability } & & \multicolumn{2}{c}{ Mean differences } \\
\cline { 2 - 3 } & PTB & PTB-TDP & TDP & & Adults & 1978 juveniles & Heritability \\
\hline Weight, g & 75 & 63 & 68 & & $1.23(6.8)^{* *}$ & $.80^{* *}$ & .85 \\
Wing, mm & 81 & 71 & 76 & & $-.89(1.3)$ & -1.04 & .89 \\
Beak length, mm & 94 & 93 & 92 & & $-.01(.1)$ & .05 & .67 \\
Beak depth, mm & 96 & 93 & 95 & & $-.06(.6)$ & .01 & .82 \\
Beak width, mm & 99 & 98 & 98 & & $-.06(.7)^{* *}$ & .03 & .90 \\
Sample sizes (range) & $120-138$ & 42 & $62-67$ & & & \\
\hline
\end{tabular}

Finch Morphology. - Adult and juvenile finches (at least 8 weeks old) were measured when banded. Five measurements (body weight, wing length, beak length, beak depth and beak width) were taken as described in Grant et al. (1975) and Boag (1983).

Measurement Error.-Measurements were taken by three observers during the course of the study reported here: by $P$. R. Grant in 1975 and 1982, by P. T. Boag between 1976 and 1978 and by T. D. Price between 1979 and 1981. Nearly all the comparisons involve measurements taken by either P. T. Boag or T. D. Price. To interpret the results it is important to assess the magnitude of differences in measuring techniques between observers, and differences among characters in the degree to which they can be accurately measured. In Table 2 we present repeatability measures, estimated as the intra-class correlation coefficient in a one way analysis of variance using two measurements per bird in each cell. The measurements were taken between 3 days and 5 years apart. Repeatabilities for beak measures are very high. Mean differences between observers and their significance values are also given (Table 2). Prior to all analyses P. R. Grant's measures were corrected to $P$. T. Boag's using differences calculated from a group of birds measured by both observers. For comparisons involving the years 1979-1981 measurements have also been corrected to T. D. Price's by adding the differences given in Table 2, separately for juveniles hatched in 1978 and for adults.

Of major concern here is the reliability and meaning of the different measures, both individually and when compared with each other. Traditional measures of body size, such as weight and wing length, have moderate repeatabilities and heritabilities (Table 2). Beak measures have distinctly higher repeatabilities. Parametric correlations between these characters and weight and wing length, when measured on a logarithmic scale, exceed .75 (Boag, 1983).

Other Sources of Variation. - To study the possibility of selection on juveniles we will rely heavily on comparisons between juveniles and the adult breeding population from which they were descended. Several sources of bias which could affect size differences for non-selective reasons were removed prior to making these comparisons. Adults include all breeding females and a randomly drawn equivalent number of breeding males. Inclusion of equal numbers of adult males and females avoids biases in size which could arise from the larger size of males (Boag and Grant, 1981), and the larger numbers of males measured. Inclusion of only breeding birds removes effects of selection on adults prior to breeding, such as earlier maturation of 
TABLE 3. Growth estimates. The table shows absolute differences between measurements of a group 24 months old and recaptured at $>8$ months old. For the 1978 cohort we also give estimates of growth from approximately one year to 2-3 years old (in italics). To correct for differences in measurements between years absolute differences between a group of adults measured at the same times as the juveniles were added to the first measurement of the juveniles. Significance values are from paired $t$ tests. ${ }^{*} P<.05$, ** $P<.01$.

\begin{tabular}{lccccc}
\hline \hline & \multicolumn{5}{c}{ Cohorts by years } \\
\cline { 2 - 6 } & 1975 & 1976 & 1978 & $\begin{array}{c}1978 \\
\text { (older) }\end{array}$ & 1981 \\
\hline Weight, g & -.08 & $-.70^{* *}$ & $-.49^{* *}$ & $.51^{* *}$ & .17 \\
Wing length, mm & $2.2^{* *}$ & $-1.5^{* *}$ & -.2 & $1.76^{* *}$ & -.3 \\
Beak length, mm & $.16^{* *}$ & -.10 & .06 & $.12^{*}$ & .11 \\
Beak depth, mm & .03 & .02 & $.07^{*}$ & -.07 & $.11^{*}$ \\
$\begin{array}{l}\text { Beak width, mm } \\
\text { Sample size }\end{array}$ & $.05^{* *}$ & .02 & $.09^{* *}$ & $.05^{* *}$ & $.09^{* *}$ \\
$\begin{array}{l}\text { Average age (days) at } \\
\text { first measurement }\end{array}$ & 49 & 13 & 42 & 31 & 17 \\
$\begin{array}{l}\text { Average age (days) at } \\
\text { second measurement }\end{array}$ & $?$ & 80 & 80 & 350 & 68 \\
\hline
\end{tabular}

small females or sexual selection on males (Price, 1984). Finally, the few $(N<5$ in each year) $G$. fortis that hybridized with immigrant Small Ground finches, $G$. $f u$ liginosa, (Grant and Price, 1981), and their offspring, have been excluded from the comparisons here.

It is also important to minimize a potential bias arising from the measurement of juveniles at a time when growth is incomplete. Juveniles were usually measured at the end of the breeding season in each year when they were between 2 and 4 months old (Table 1). Some juveniles were recaptured at about one year later. Estimates of their growth are presented in Table 3. Juvenile samples comprise only those birds known to have hatched on the island and to be over 56 days old, except for the 1975 sample which possibly includes some immigrants or younger birds. Growth between the two measurement periods for beak characters was often small. Smith and Zach (1979) found similar results for beak growth in a population of song sparrows, Melospiza melodia. Weight actually decreased between the two measurement periods. Changes in wing length varied in direction, and were sometimes large.
We also give growth estimates from age one year to age 2-3 years for the only cohort (1978) providing sufficient data. These estimates show that all characters continued to grow to a small extent beyond the age of one year, except for beak depth. Wing length is known to continue to grow in several passerine species (e.g., Searcy, 1979; Payne, 1982) associated with molts which usually occur annually. We will concentrate on the character beak depth, which did not show further growth.

\section{RESULTS}

In Table 4 we compare breeding adults with a sample of juveniles known to be present on the island in January of the following year. Juveniles are 7-10 months old at this time. For the comparisons following the 1975 and 1979 breeding seasons we use only measurements of juveniles captured at an age of 7-10 months. For the other comparisons the sample includes (for 1976) or comprises (for 1978 and 1981) juveniles measured at age 24 months and growth-corrected according to Table 3 .

In all 5 years the juveniles were smaller than the adults. Many of the comparisons are significant, and combined probability 


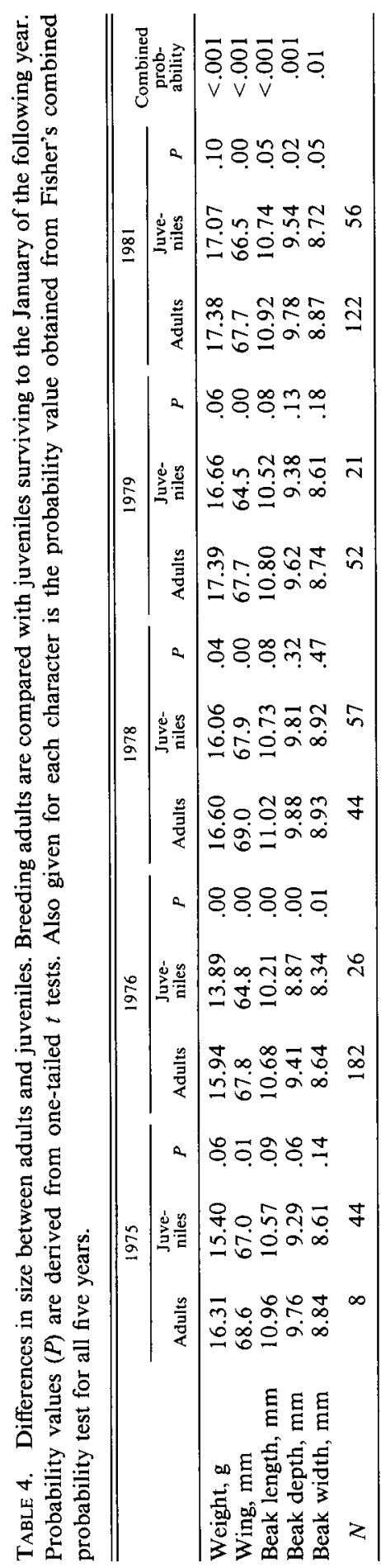

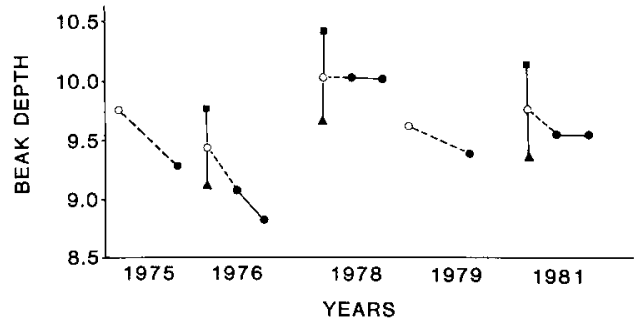

FIG. 1. Sample means for the character beak depth: breeding adults, with males $(\square)$ and females (A) given separately for the years 1976,1978 and 1981. The symbol - juveniles; lines connecting two such symbols represent the same cohort of juveniles at different times. Dashed lines connect breeding adults with the offspring generation of that year. All juvenile measurements have been corrected for growth using values in Table 3 , and standardized to T. D. Price's measurements.

values are highly significant for all characters (Table 4). Results for the character beak depth are illustrated in Figure 1. As discussed below these size differences between cohorts probably indicate some selection against large juveniles.

Direct Observations of Selection. - It has not been possible to detect selection on juveniles by measuring them in the nest (Table 5). This is not unexpected, particularly when starvation is the cause of mortality. Relatively heavy weight in the nest is generally a sign of good health and in several studies correlates with future survival probability (Perrins, 1965, 1980; Howe, 1976). Thus much of the size variation, particularly among juveniles disappearing, may be environmentally determined and not related to size which would be attained when birds are fully grown. Additionally, nestling size differences are confounded by age differences.

There is evidence of selection against large 2-month-old juveniles over their next few months of life. In 1976 and 1981 there was differential survival of the smaller juveniles (Table 6). A multivariate analysis of variance of morphological measurements (excluding the character wing length) shows the differences between surviving and disappearing juve- 
TABLE 5. Mean weights in grams of nestlings which survived and those which disappeared. Measurements were taken at age 8-10 days. Survival to age 7 months is shown for 1979; in other years survival is up to age 2-4 months (see text). Percent mortality gives the proportion disappearing over the time period. There are no significant differences between those surviving and those disappearing ( $t$ tests).

\begin{tabular}{|c|c|c|c|c|c|c|}
\hline & \multicolumn{4}{|c|}{ Mean weights of those which } & \multirow{2}{*}{$\begin{array}{l}\% \text { difference } \\
\text { in size }\end{array}$} & \multirow[b]{2}{*}{$\%$ mortality } \\
\hline & Died & $N$ & Survived & $N$ & & \\
\hline 1976 & 12.68 & 277 & 12.86 & 107 & 1.42 & 72 \\
\hline 1978 & 12.87 & 52 & 13.14 & 172 & 2.06 & 23 \\
\hline 1979 & 12.59 & 58 & 12.70 & 27 & .87 & 68 \\
\hline 1981 & 13.97 & 66 & 13.93 & 128 & -.29 & 34 \\
\hline
\end{tabular}

niles to be almost significant $(F(4,72)=$ $2.18, P=.08$ for 1976 and $F(4,82)=2.18$, $P=.08$ for 1981). In the other year for which comparisons are possible (1978) there was no significant selection. This parallels observations on the size differences between adults and juveniles (Fig. 1, Table 4).

Causes of Juvenile Disappearance.Disappearance of juveniles could result from either mortality or emigration. It is important to assess the magnitude of emigration but very difficult to do so. The following evidence suggests that although some emigration does occur it is of minor importance in comparison with mortality.

First, $15(19 \%)$ of the fledged juveniles thought to have disappeared in July 1981 were recorded on the island in 1982. A transect over the whole island was conducted on the last day of the July 1981 field season and all observed juveniles were recorded. By using the Lincoln In- dex method (Southwood, 1966) we estimate that four juveniles \pm 5 (95\% confidence limits) were present on the island and never observed. Therefore six or more of the 15 unobserved juveniles had probably emigrated temporarily. Second, no banded individuals from Daphne Major were recorded on Daphne Minor. However two of 16 juveniles (13\%) banded on I. Daphne Minor were subsequently recorded on I. Daphne Major, and one of these established a territory, but did not breed, and was found dead in 1982. The Daphne islands are close together and probably exchange individuals more with each other than with other Galápagos islands. The main conclusion is that emigration is subsidiary to mortality as a cause of juvenile disappearance.

Causes of Mortality. - In Figure 2 we present estimates of chick survival from age 8 days to the end of the breeding season (i.e., at age 2-4 months), and subsequent survival to the following year (i.e.,

TABLE 6. Selection on juveniles from age 2-4 months over the next 6 months of life. All measurements were made at age 2-4 months. The table gives measurements of the juveniles at this age ('before'), and measurements of the subsection known to be alive 6 months later ('after'). There are no data available for other years. Significance values are for one-tailed $t$ tests in a comparison of survivors with those that disappeared. $* P<.05$.

\begin{tabular}{|c|c|c|c|c|c|c|}
\hline & \multicolumn{2}{|c|}{1976} & \multicolumn{2}{|c|}{1978} & \multicolumn{2}{|c|}{1981} \\
\hline & Before & After & Before & After & Before & After \\
\hline Weight, $\mathrm{g}$ & 15.16 & 14.75 & 16.32 & 16.50 & 17.80 & $16.90^{*}$ \\
\hline Wing length, mm & 66.2 & 66.3 & 67.8 & 68.0 & 66.8 & 66.8 \\
\hline Beak length, mm & 10.33 & 10.18 & 10.77 & 10.68 & 10.68 & 10.65 \\
\hline Beak depth, mm & 9.00 & $8.73^{*}$ & 9.75 & 9.73 & 9.44 & 9.43 \\
\hline Beak width, mm & 8.48 & $8.27^{*}$ & 8.83 & 8.81 & 8.69 & $8.63^{*}$ \\
\hline$N$ & 77 & 20 & 89 & 57 & 87 & 56 \\
\hline
\end{tabular}




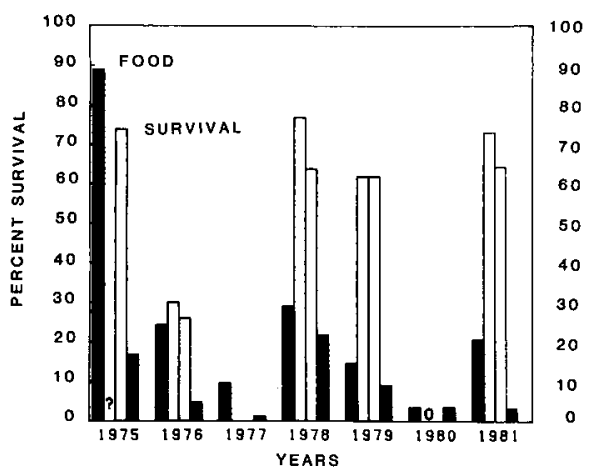

FIG. 2. Food abundance and the proportion of juveniles surviving. The shaded histograms show food abundance. For each year, the left column is the abundance of food in June and the right column the abundance in the following January. Food abundance is given in $\mathrm{mg} / 50 \mathrm{~m}^{2}$ bird of small soft seeds (see text). The unshaded columns represent survival from age 8 days to $2-4$ months (left side), and survival for the 6 subsequent months (right side), respectively. ? indicates data not available, and 0 indicates no survival. In 1979, data are available only for the period age 8 days to 8 months, and mortality has been assumed to occur equally in the two separate periods.

at age 8-12 months), and relate these to the food supply. Food supply is given in $\mathrm{mg} / 50 \mathrm{~m}^{2} /$ bird of small soft seeds (geometric mean of depth and hardness, $\sqrt{D H},<3.0$ ) because juveniles are unable to handle larger, harder seeds (see below), and because other easily handled foods (caterpillars and pollen) disappear soon after finches have finished breeding. After June there is very little new seed production and juveniles are dependent on a standing crop of seeds until October when the Opuntia cactus starts to flower. All finches on the island, including juveniles and adults of all Geospiza species, are included in the quotient. This overestimates relative food availability in 1975 and 1976 when a much higher proportion of adults fed on small seeds than in subsequent years (Boag and Grant, 1981).

An association of food abundance and nestling survival is apparent. In years of low food abundance, e.g., 1980, fledged

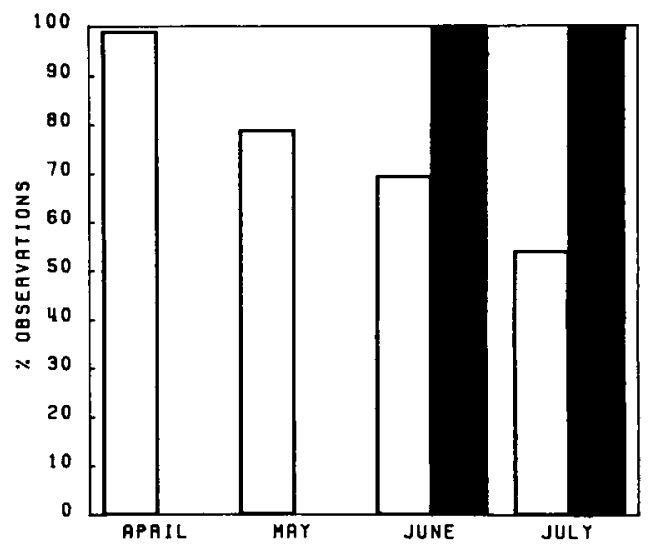

FIG. 3. The proportion of adults (unshaded) and juveniles (shaded) feeding on easily handled foods (see text) in 1981. Based on 100-300 point observations in each month.

chicks well below typical fledging weights could be captured by hand. In other years this was not possible. The observations suggest fledglings die from starvation. Several studies on the Galápagos have identified other possible sources of mortality and concluded that food supply is of major importance in limiting finch numbers (Grant et al., 1975; Smith et al., 1978; Grant and Grant, 1980a, 1980b; Boag, 1981; Boag and Grant, 1981: Schluter, 1982).

If food shortage is the major cause of mortality chicks that grow to a small size will have a relative energetic advantage over those growing to larger sizes, provided that all chicks receive similar quantities of food. Parents do not appear to feed chicks preferentially. In more than 200 hours of nest watches the only feeding discrimination by parents we observed was against unhealthy nestlings that were pushed aside by their sibs and failed to fledge.

Small juveniles retain a potential energetic advantage over large juveniles as a result of lower daily energy requirements. There appears to be no balancing advantages to large size associated with feeding. Sims (1955) showed that juvenile Hawfinches, Coccothraustes coc- 


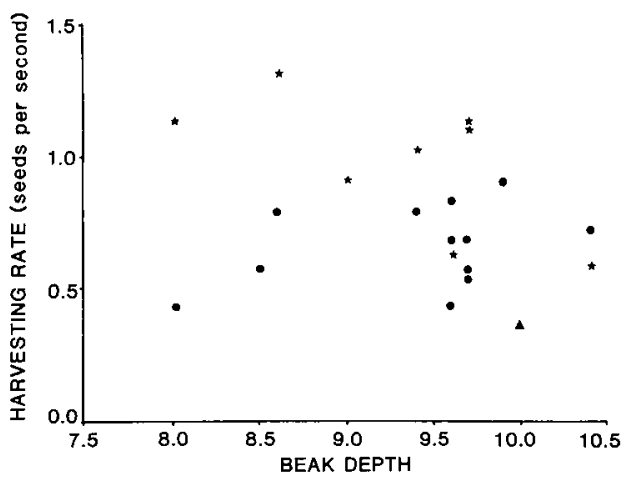

FIG. 4. The number of seeds taken per second plotted against beak depth for Geospiza fortis juveniles approximately 65 days old (1981 data). $\star$ seeds taken from the ground. seeds taken from Portulaca plants. $\Delta$ seeds taken from Amaranthus plants.

cothraustes, are unable to crack hard seeds for their first few months of life, because their skulls are not fully ossified and their beaks are too soft and not structurally fully developed. Probably for similar mechanical reasons, juvenile $G$. fortis do not crack hard seeds such as Opuntia $(\sqrt{D H}=3.25)$ or Tribulus $(\sqrt{D H}=$ 8.68). They were often seen pecking at Opuntia seeds and eating the aril, which adults rarely do. Thus as food abundance declined and adults began to feed on these hard and large seeds juveniles remained feeding on the small soft seeds (Fig. 3). Large adults have a selective advantage over small adults in terms of seed cracking ability (Grant et al., 1976; Boag and Grant, 1981; Grant, $1981 b$; Grant and Grant, 1982), but there is no suggestion of an advantage to large individuals when feeding on small seeds. Indeed, among juveniles in 1981 (Fig. 4) there is a negative correlation between beak depth and harvesting rate ( $r=-.23, N=22$, ns) i.e., the correlation is in the direction of giving small birds a feeding advantage.

The advantage of small size among juveniles is shown by a comparison between species. Geospiza scandens, the Cactus finch, breeds on I. Daphne Major, and juveniles feed on the same small seeds as Geospiza fortis. This species is $30 \%$ heavier in body weight, and juveniles suf- fer significantly heavier mortality (Boag, 1981).

\section{DISCUSSION}

One clear prediction of the hypothesis that large juveniles are at a selective disadvantage is that the sex ratio should become skewed in favor of females, because females are on the average $4-5 \%$ smaller than males (Boag and Grant, 1981). Unfortunately, the sex of all birds can only be determined (without laparotomy) by plumage traits when they are at least 18 months old. During the present study only the 1978 and 1979 cohorts reached this age. These cohorts were apparently subject to the least selection (Table 3) while juveniles, but had been subject to selection for large size later (Price, unpubl.). Thus by 1981 there were 75 males and 41 females in the 1978 cohort but only 8 males and 12 females in the 1979 cohort. The data are equivocal.

The skewed sex ratio prediction would be tested better in species which are more strongly sexually dimorphic. In fact several such studies have been made, and the results suggest that selection acting on body size in young birds may be quite general. Thus skewed sex ratios found by Holcomb and Tweist (1970), Howe (1976, 1977) and Moss (1980) may be interpreted as differential mortality of the larger sex; differential mortality was directly observed by Howe. When food is more plentiful the smaller sex has been observed to mature more rapidly in two studies (Newton, 1978; Fiala, 1981). Rapid maturation may be important in sib-sib competition (Werschkul and Jackson, 1979) as well as in the rapid development of such skills as feeding and begging from parents once fledged. Sex ratio studies have often been interpreted in terms of optimization of the sex ratio arguments (e.g., Williams, 1979; Burley, 1982). These arguments assume an absence of selection on body size, yet especially in these strongly dimorphic species both natural and sexual selection are likely to be operating.

The major alternative to a selection 
hypothesis in accounting for adult-juvenile size differences is that growth approaches different asymptotes in different years, or takes much longer than 710 months to complete in some years. Neither possibility can be directly tested, although estimated growth increments in such years as 1976 (Table 3) hardly appear sufficient to account for the substantial differences between juveniles and adults, such as were observed in that year.

Although males are not known to have bred until their second year, females may breed when less than one year old (this has been observed in 1976 and 1979). Thus any lasting differences in growth between cohorts should contribute to environmental variance when these cohorts form the breeding population. Despite that, less than $20 \%$ of the phenotypic variance is attributable to environmental effects for some characters (Table 2). The high heritability estimates do appear to be due to the presence of additive genetic variance, and are probably not significantly inflated by maternal effects or geneenvironment correlations (Boag and Grant, 1978; Grant and Price, 1981; Boag, 1983).

Selection against large juveniles is extremely difficult to demonstrate. It is not possible to unambiguously reject the alternative growth hypothesis. Nevertheless the evidence is consistent with the hypothesis that some or all of the selection favoring large body size in adults is countered by selection favoring small body size in juveniles. Assuming this we proceed to discuss the implications of such selection on juveniles for the evolution of morphological and life history traits.

Morphological Evolution. - Juvenile size when almost full grown (i.e., at 60 days old) is positively correlated with size at age 8 days (for beak depth in $1981 r=$ $.61, N=85, P<.001)$. In addition high genetic correlations between nestling and adult size have been found in two species of Darwin's finch, including $G$. fortis (Boag, 1983; Grant, 1981a; Price, unpubl.).
However, provided that the genetic correlation between adult and juvenile body size is not perfect it might be thought that the opposing selection pressures should have led to evolutionary responses in both directions, resulting in a delay in juvenile growth, and the future absence of such selection. This has not occurred, probably because a delay in growth implies a delay in tissue maturation (Ricklefs, 1979). Maturation of the beak, in particular, results in improved feeding ability, notably for the larger individuals which can only then handle the large seeds. Thus any delay in growth is not expected.

Short term evolutionary consequences depend on the timing of breeding with respect to selection events. Most observed reproduction has been by finches at least two years old (i.e., adults). However, some females have bred when less than one year old. These females were smaller than similar-aged females that did not breed (Price, 1984), suggesting that the survival advantage over the first year of life may be amplified by a reproductive advantage. If this reproductive advantage is found to occur in both sexes in some years it could be another general selection force opposing the selection for large size in both sexes associated with adult mortality (Boag and Grant, 1981).

Given the opposing selection pressures on body size, morphological evolution can proceed either by an intensification of selection at one stage of the life history or relaxation at another stage. Relaxation of selection implies population growth with little mortality, whereas intensification implies heavy mortality. The two processes may be coupled: for example very heavy mortality and intense selection in 1977 (Boag and Grant, 1981) resulted in low finch abundance in 1978, and as a probable consequence there was relaxed selection on the juveniles in that year (Table 4, Fig. 1).

Life History Evolution. - Because body size is highly heritable and correlated between adults and juveniles, and also a major determinant of adult survival, the 
selection against large juveniles implies a negative genetic covariance between juvenile and adult survival. Mortality schedules of both adults and juveniles in this population can be understood in terms of this assumed negative covariance. The fluctuating directional selection on body size at different stages of the life history is likely to give rise to overall stabilizing selection, which may be quite weak. Under these circumstances a high additive genetic variance for body size, and hence for these survival traits, can be maintained under weak stabilizing selection through mutation and immigration input (Lande, 1976; Grant and Price, 1981). Thus overall fitness may have low heritability, even though the components of fitness have high heritabilities. This sort of relationship between life history traits has been termed 'antagonistic pleiotropy' (e.g., Rose, 1983).

The relationship between these two life history traits and other life history traits, such as fecundity and age at maturity, can be investigated by looking for the presence or absence of selection on body size at other life history stages. To illustrate this approach we consider a third life history trait-reproductive effort. Two indices of reproductive effort, clutch size and number of chicks fledged, were found to be only weakly correlated with morphology (Price, 1984). This has two implications. First, there is little genetic covariance between these traits and probability of adult mortality when morphology largely determines this probability. Second, mean reproductive effort in this population is either determined by unidentified trade-offs with other life history traits, or is under direct stabilizing selection. Stabilizing selection has been identified and discussed as the determinant of mean reproductive effort for many bird species (e.g., van Noordwijk et al., 1980), although often in somewhat different language (Lack, 1966). It can be thought of as the product of two opposing directional selection pressures: to have more offspring, and to have well-fed offspring (Lack, 1966; Falconer, $1981 \mathrm{Ch}$.
20). In general the possibility of tradeoffs between reproductive effort and adult mortality has been subject to a great deal of investigation, with the cost of greater reproductive effort assumed to be an acceleration of senescence (e.g., Rose and Charlesworth, 1981). In the present study morphology, and not senescence, appeared to be the major determinant of differential survival of individuals (Boag and Grant, 1981).

Conclusions. - The average genetic covariance between life history traits indicates its probable importance in affecting the evolution of these traits. Studies such as this also demonstrate how widely varying environmental conditions (Fig. 2) lead to quite different selection pressures which affect the way in which the traits covary, and can indicate how covariances are likely to be affected when causes of mortality vary. Without such observations it may be difficult to interpret laboratory results (Stearns, $1982 a, 1982 b$ ) or measurements of phenotypic correlations between life history traits obtained in natural populations (Smith, 1981).

Our use of observed selection to infer genetic covariances between life history traits depended on two previous observations: (1) measures of body size are highly heritable and (2) much of the variance in adult mortality is body size dependent. Given that adult and juvenile body sizes are highly correlated and essentially the same character, body size could be used as a 'genetic marker' in looking for covariances between adult mortality and other life history traits. However, in this study the approach suffered from the fact that we were not able to conclusively demonstrate selection against large juveniles.

Whether the approach can be used generally in nature is problematical. Often mortality may be due to a variety of causes acting on several heritable traits, some of which may be very difficult to measure. Nevertheless body size is commonly found to be associated with life history traits both interspecifically (Blueweiss et 
al., 1978) and intraspecifically (e.g., Hegmann and Dingle, 1982). Highly heritable measures of body size may be found in other species if body size measures with high repeatability are used. Estimates of components of variance in body size, combined with correlations between body size and life history traits in nature, should provide one useful avenue towards understanding life history evolution.

\section{SuMMARY}

We consider the possibility of selection favoring small body size in a population of Darwin's Medium Ground finches (Geospiza fortis). Juveniles, when close to fully grown, are often substantially smaller on average than the adult breeding population from which they are descended. Some weak selection favoring small body size has been observed from age $2-4$ months to age $7-10$ months. It is difficult to completely eliminate the possibility of delayed growth effects; nevertheless it is likely that there is some selection against large juveniles. This opposes selection against small adults which is known to occur regularly. A plausible selection pressure is a metabolic disadvantage to large juveniles. The strength of the observed selection varies in association with varying environmental conditions.

Patterns of adult and juvenile mortality in this population can be understood as resulting from a negative covariance between these two traits, mediated by body size. Since body size is highly heritable this covariance is largely genetic. Observations of selection on highly heritable traits provide a useful, previously unexplored, approach to the investigation of life history evolution.

\section{ACKNOWLEDGMENTS}

We thank Ayse Unal and Spike Millington for assistance on Daphne, and Peter Boag for making his data available. J. Fry, H. L. Gibbs, R. Lande, P. Myers, D. Schluter, and P. E. Smouse commented on the manuscript, which was originally typed by Mao. The research was sup- ported by NSF grants DEB-77-23377 and DEB-79-21119 to PRG, with some additional funding by the Frank M. Chapman fund to TDP, and was carried out under the auspices of the Dirección General de Desarrollo Forestal, Quito, and the Charles Darwin Research Station.

\section{Literature Cited}

Aвbott, I., L. K. Aвbott, and P. R. Grant. 1977. Comparative ecology of Galápagos ground finches (Geospiza Gould): evaluation of the importance of floristic diversity and interspecific competition. Ecol. Monogr. 47:151-184.

Blueweiss, L., H. Fox, J. Kudzma, D. NaKashima, R. Peters, And S. SAms. 1978. Relationships between body size and some life history parameters. Oecologia 37:257-272.

BOAG, P. T. 1981. Morphological variation in the Darwin's finches (Geospizinae) of Daphne Major Island, Galápagos. Unpubl. Ph.D. thesis. McGill Univ.

- 1983. The heritability of external morphology in Darwin's ground finches (Geospiza) on Isla Daphne Major, Galápagos. Evolution 37:877-894.

Boag, P. T., ANd P. R. Grant. 1978. Heritability of external morphology in Darwin's finches. Nature 274:793-794.

- 1981. Intense natural selection in a population of Darwin's finches (Geospizinae) in the Galápagos. Science 214:82-85.

Burley, N. 1982. Facultative sex ratio manipulation. Amer. Natur. 120:81-107.

Dingle, H., AND J. P. Hegmann, eds. 1982. Evolution and Genetics of Life Histories. SpringerVerlag, N.Y.

ETGES, W. J. 1982. 'A new view of life history evolution?'-a response. Oikos 38:118-122.

FAlCoNER, D. S. 1981. Introduction to Quantitative Genetics, 2 nd ed. Ronald, N.Y.

FIALA, K. 1981. Reproductive cost and the sex ratio in Red Winged Blackbirds, p. 198-216. In R. D. Alexander and D. W. Tinkle (eds.), Natural Selection and Social Behavior: Recent Research and New Theory. Chiron, N.Y.

Giesel, J. T., P. Murphy, AND M. Manlove. 1982. An investigation of the effects of temperature on the genetic organization of life history indices in three populations of Drosophila melanogaster, p. 189-207. In H. Dingle and J. P. Hegmann (eds.), Evolution and Genetics of Life Histories. Springer-Verlag, N.Y.

Grant, B. R., AND P. R. Grant. 1982. Niche shifts and competition in Darwin's finches: $G e$ ospiza conirostris and congeners. Evolution 36 : $637-657$.

Grant, P. R. 1981a. Patterns of growth in Darwin's finches. Proc. Roy. Soc. London B 212: 403-432.

- 1981b. The feeding of Darwin's finches 
on Tribulus cistoides (L.) seeds. Anim. Behav. 29:785-793.

Grant, P. R., AND P. T. BoAG. 1980. Rainfall on the Galápagos and the demography of Darwin's finches. Auk 97:227-244.

Grant, P. R., AND B. R. Grant. 1980a. Annual variation in finch numbers, foraging and food supply on Isla Daphne Major, Galápagos. Oecologia 46:55-62.

- 1980b. The breeding and feeding characteristics of Darwin's finches on Isla Genovesa, Galápagos. Ecol. Monogr. 50:381-410.

Grant, P. R., B. R. Grant, J. N. M. Smith, I. J. AвBOTr, AND L. K. AвBOTt. 1976. Darwin's finches: population variation and natural selection. Proc. Nat. Acad. Sci. USA 73:257-261.

Grant, P. R., AND T. D. Price. 1981. Population variation in continuously varying traits as an ecological genetics problem. Amer. Zool. 21:795811.

Grant, P. R., T. D. Price, and H. Snell. 1980. The exploration of I. Daphne Minor. Noticias de Galápagos 31:22-28.

Grant, P. R., J. N. M. Smith, B. R. Grant, I. Aвbott, AND L. K. AbBott. 1975. Finch numbers, owl predation and food supply on Isla Daphne Major, Galápagos. Oecologia 19:239257.

Hegmann, J. P., and H. Dingle. 1982. Phenotypic and genetic covariance structure in milkweed bug covariance life history traits, p. 177185. In H. Dingle and J. P. Hegmann (eds.), Evolution and Genetics of Life Histories. Springer-Verlag, N.Y.

Holcomb, L. C., AND G. Tweist. 1970. Growth rates and sex ratios of Red-winged Blackbird nestlings. Wilson Bull. 82:294-303.

HowE, H. F. 1976. Egg size, hatching asynchrony, sex, and brood reduction in the Common Grackle. Ecology 57:1195-1207.

-1977. Sex ratio adjustment in the Common Grackle. Science 198:744-746.

LACK, D. 1966. Population Studies of Birds. Clarendon, Oxford.

LANDE, R. 1976. The maintenance of genetic variability by mutation in a polygenic character with linked loci. Genet. Res. 26:221-235.

-1982. A quantitative genetic theory of life history evolution. Ecology 63:607-615.

Moss, R. 1980. Why are Capercaillie cocks so big? Brit. Birds 73:440-447.

MYERS, J. H. 1978. Sex ratio adjustment under food stress: maximization of quality or numbers of offspring? Amer. Natur. 112:381-388.

Newton, I. 1978. Feeding and development of Sparrowhawk Accipiter nisus nestlings. J. Zool. London 184:465-487.

van NoOrdwiJk, A. J., J. H. van Balen, AND W. SCHARLOO. 1980. Heritability of ecologically important traits in the Great Tit. Ardea 68:193203.
PAYNE, R. B. 1982. Ecological consequences of song matching: breeding success and intraspecific song mimicry in Indigo Buntings. Ecology 63:401-411.

Perrins, C. M. 1965. Population fluctuations and clutch size in the Great Tit, Parus major. J. Anim. Ecol. 34:601-647.

- 1980. Survival of young Great Tits, Parus major. Proc. 18th Internat. Ornithol. Congr., Berlin, 1978, p. 159-174.

Price, T. D. 1984. The evolution of sexual size dimorphism in Darwin's finches. Amer. Natur. 123:500-518.

RICKLEFS, R. E. 1979. Adaptation, constraint and compromise in avian postnatal development. Biol. Rev. 54:269-290.

Rose, M. R. 1983. Theories of life history evolution. Amer. Zool. 23:15-23.

Rose, M. R., and B. Charlesworth. 1981. Genetics of life history in Drosophila melanogaster. 1. Sib analysis of adult females. Genetics 97:173-186.

SCHLUTER, D. 1982. Distributions of Galapagos ground finches along an altitudinal gradient: the importance of food supply. Ecology 63:15041517.

SEARCY, W. A. 1979. Morphological correlates of reproductive success in captive male Red-winged blackbirds. Condor 81:417-420.

SIMS, R. W. 1955. The morphology of the head of the Hawfinch. Bull. Brit. Mus. Nat. Hist. 2: 369-393.

Smith, J. N. M. 1981. Does high fecundity reduce survival in song sparrows? Evolution 35:11421148.

Smith, J. N. M., P. R. Grant, B. R. Grant, I. J. AbBotr, AND L. K. Aвbott. 1978. Seasonal variation in feeding habits of Darwin's ground finches. Ecology 59:1137-1150.

Smith, J. N. M., AND R. ZACH. 1979. Heritability of some morphological characters in a song sparrow population. Evolution 33:460-467.

SouTHwood, T. R. E. 1966. Ecological Methods with Particular Reference to the Study of Insect Populations. Methuen, London.

SteARNS, S. J. 1980. A new view of life history evolution. Oikos 35:266-281.

- $1982 a$. Reply to Etges. Oikos 38:122-124. 218:463-464

WerschKUL, D. B., AND J. A. JACKSON. 1979. Sibling competition and avian growth rates. Ibis 121:97-102.

Williams, G. C. 1979. The question of adaptive sex ratio in outcrossed vertebrates. Proc. Roy. Soc. London B 205:567-580.

Corresponding Editor: J. A. Endler 